\title{
KORO EPIDEMIC: A DESCRIPTIVE STUDY
}

\author{
Siddhartha Debbarma1, Swapan Kumar Das ${ }^{2}$, Aman Kumar33, Deep Debbarma 4 , Abhijit Das 5 , Taranga Reang ${ }^{6}$
}

${ }^{1}$ Assistant Professor, Department of Psychiatry, Agartala Govt. Medical College \& GBP Hospital.

${ }^{2}$ Assistant Professor, Department of General Medicine, Agartala Govt. Medical College \& GBP Hospital.

3Postgraduate, Department of Community Medicine, Agartala Govt. Medical College \& GBP Hospital.

${ }^{4}$ Medical Officer, Department of Community Medicine, Agartala Govt. Medical College \& GBP Hospital.

5 Medical Officer, Department of Community Medicine, Agartala Govt. Medical College \& GBP Hospital.

${ }_{6}^{6}$ Assistant Professor, Department of Community Medicine, Agartala Govt. Medical College \& GBP Hospital.

\section{ABSTRACT}

\section{BACKGROUND}

A massive Koro epidemic hit Tripura in 2015. This is probably the sixth Koro epidemic in India.

\section{OBJECTIVE}

The objective was to identify profile of affected persons for such conditions.

\section{METHODOLOGY}

The present paper deals with the descriptions of 57 Koro cases in Tripura. The different aspects of the epidemic including clinical presentation, health seeking behaviour, folk treatments and preventive strategies are discussed from transcultural perspective.

\section{RESULT}

Younger males were predominantly affected. Poor literacy and socio-economic conditions were the likely contributing factors. Male patients have almost similar symptoms of presentation like shrinkage of penis, feeling weakness, tingling sensation over the genital area, palpitation, sleep disturbances and immense fear of impending death once if it enters inside abdomen. Retraction of breast and genitalia are the common presenting features among females.

\section{CONCLUSION}

Large scale IEC activities to be carried out to reach to different sections of the population in order to mitigate mass fear, anxiety and to increase the spread of rational and timely information.

\section{KEYWORDS}

Koro Epidemic, Perception, Treatment, Preventive Strategy, Koro in Tripura.

HOW TO CITE THIS ARTICLE: Debbarma S, Das SK, Kumar A, et al. Koro epidemic: a descriptive study. J. Evolution Med. Dent. Sci. 2016;5(76):5634-5638, DOI: 10.14260/jemds/2016/1271

\section{INTRODUCTION \\ Koro is a culture bound syndrome. "Koro" means in Malaysian language the "head of the turtle." Basic Chinese culture may give some clues to Koro.1,2 For many years, Chinese used the symbol of turtle to stand for longevity and vital force within a person. There was an obvious resemblance between head of long lived turtle and glans penis. According to Yap, ${ }^{3}$ fear about nocturnal emission, impotence and general debility helped generate the belief of Koro. A combination of psychological, social and cultural factors predisposes an individual to the body image distortion of Koro. Cultural concept about Koro magnifies its psychological effect on individual who suffers from it. For instance in Chinese folk belief, the Koro illness is dangerous and one may die because of it.}

Financial or Other, Competing Interest: None.

Submission 29-07-2016, Peer Review 28-08-2016,

Acceptance 03-09-2016, Published 21-09-2016.

Corresponding Author:

Dr. Taranga Reang,

Assistant Professor,

Department of Community Medicine,

Agartala Govt. Medical College \& GBP Hospital Agartala,

Tripura.

E-mail: tarangareang@gmail.com

DOI: $10.14260 /$ jemds $/ 2016 / 1271$

\section{(c) (i) $९$}

The fear that this belief generates can leave a person who experiences sexual anxiety that they associate with Koro feeling helpless and panic stricken. Koro is unlike other states of depersonalisation, in which a person might realise that they are simply spaced out because of stress. The person with Koro has only limited insight into his condition. Yet, he does not suffer more widespread emotional disturbances. Thus, Koro is a distinctive condition or a "culture bound" condition or "ethnic disorder" specific to the Chinese culture. Nevertheless, some elements of Koro have definitive parallels in other cultures. Carstairs4 found psychological disturbances among Hindu men that include idea like the Yin and Yang concept of China connected to the belief that losing semen is dangerous to a man's health. The Koro victim suffers from the delusion that his penis is shrinking and retracting into his abdomen, and that he will die when the process is complete. Another name of Koro is Suk-Yung, which means shrinking of penis. ${ }^{3}$ Koro appears to affect the younger Chinese males (21 to 40 years of age) who have the sexual history of conflict or maladjustment. As far as 700 years ago in China, people believed that health was the equilibrium between the Yang (Male) and Ying (Female) humours. During masturbation or nocturnal emission, an unhealthy loss of Yang took place putting the individual in an unbalanced condition. Most episodes of Koro occur at night. Symptoms accompanying the 
anxiety include faintness, a feeling of impending death, palpitation, trembling and a tingling sensation in the genital area. So strong is this depersonalisation that a number of men believed they must hold on to their penis all during an attack, so that it would not disappear by shrinking inside them. The need to visually inspect and touch their genitals is paramount to confirm their size and existence. 5

Outbreak of Koro is a well-known psychiatric epidemic in Asia-Pacific region. In India first such epidemic reported in 1968 in North Bengal region of West Bengal State, the second one in 1982 affected mainly West Bengal6 and Assam. ${ }^{7}$ The third mini-epidemic occurred in a village in South 24 Pargana district of West Bengal in 1988.8 Fourth Koro epidemic took place in Tripura in 1998. At that time the epicentre of the epidemic was Assam, then Mumbai and then transmitted by migrant labourers to West Bengal. ${ }^{9}$ The fifth Koro epidemic occurred in Kochi, Kerala10 and Goregaon in Maharastra11 and even in Tripura12 during December in the year 2010.

At present, the Koro epidemic again took place in Tripura since March - July 2015 in the Karbook (Gomati district); Shantir Bazar, Belonia (South District) sub-division of Tripura and rural villages of Bishalgarh sub-division under Sepahijala district. This study has been taken up for creating public awareness regarding Koro, frequently occurring in the state and future preventive strategies to be taken up by the health care professionals.

\section{METHODOLOGY}

Tripura is a state of nearly 38 lakhs of population (Census 2011)13 in the North Eastern State of India.

The majority of the indigenous tribal populations live in rural and hilly terrain of the state with poor socio-economic condition and poor literacy status.A medical team under the leadership of the author initially visited the affected villages of Karbook sub-division of Gomati district of Tripura. Later, visited South and Sepahijala district of Tripura. Affected populations were examined in the health cum awareness camp and survey also conducted for Koro symptoms in the villages viz. Ichachari, Purbamanikya Dewan and Patichari included under ADC (Autonomous District Council) area of the state. The subjects were selected purposively from the villages and camps and descriptive study such as field survey, observation and clinical examination were performed. Information was collected partly by observation from the local people, health care workers; clinical examination and interview of the participants. The study was carried out during May to July 2015. Cases who did not refuse and acutely suffering from the disease were included in the study. The present report was based on the individual case study reported to the Karbook Community Health Centre (CHC) and interview of the affected person during our field visit at Patichari village of Karbook sub-division. Later the author from his own interest visited the villages' ofShantir bazaar and Sabroom subdivisions under South district and Sepahijala district for gathering further information. Informed consent was obtained from the patients before conducting the interview and clinical examination. Diagnostic assessments were done following ICD 10 criteria (WHO, 1991). This study contains the salient clinical features, beliefs regarding the illness and different folk treatments adopted by the affected persons. We assessed them clinically and mental state examination conducted by Psychiatrist.

\section{RESULT AND OBSERVATIONS}

\section{The Cases}

A total of 57, out of which 6 (six) admitted cases at Karbook CHC and 51 cases history taken during our field visit from the rural areas of Karbook sub-division. Many of them were illiterate or up to primary level of education and low income group either unemployed or day labourer. They belong to tribal community and majority were Hindu. Only $21.43 \%$ reported to be Buddhist by religion (Table 1).

All male patients have almost similar symptoms of presentation like shrinkage of penis, feeling weakness, tingling sensation over the genital area, palpitation, sleep disturbances and immense fear of impending death once if it enters inside abdomen. Retraction of breast and genitalia are the common presenting features among females. All other symptoms are similar with the male counter parts (Table 2).

\begin{tabular}{|c|c|c|c|}
\hline \multicolumn{2}{|c|}{ Variables } & No. (N) & (\%) \\
\hline \multirow{3}{*}{ Age Group (yrs.) } & $17-30$ & 29 & $50.87 \%$ \\
\hline & $31-45$ & 16 & $28.07 \%$ \\
\hline & $46-60$ & 12 & $21.05 \%$ \\
\hline \multirow{2}{*}{ Sex } & Male & 49 & $85.71 \%$ \\
\hline & Female & 8 & $14.03 \%$ \\
\hline \multirow{2}{*}{ Marital Status } & Married & 45 & $78.57 \%$ \\
\hline & Unmarried & 12 & $21.43 \%$ \\
\hline \multirow{5}{*}{ Literacy Status } & Illiterate & 12 & $21.43 \%$ \\
\hline & Primary & 29 & $50.00 \%$ \\
\hline & Metric & 12 & $21.43 \%$ \\
\hline & Higher Secondary & 04 & $7.14 \%$ \\
\hline & Graduate \& above & 00 & $0.00 \%$ \\
\hline \multirow{4}{*}{ Religion } & Hindu & 45 & $78.57 \%$ \\
\hline & Christian & 00 & $0.00 \%$ \\
\hline & Buddhist & 12 & $21.43 \%$ \\
\hline & Muslim & 00 & $0.00 \%$ \\
\hline \multirow{5}{*}{ Occupation } & Unemployed & 20 & $35.08 \%$ \\
\hline & Employed & 01 & $1.75 \%$ \\
\hline & Farmer & 6 & $10.53 \%$ \\
\hline & Day labourer & 28 & $49.12 \%$ \\
\hline & Student & 2 & $3.51 \%$ \\
\hline \multirow[b]{2}{*}{ Income } & $<=$ Rs.5000/- & 37 & $64.28 \%$ \\
\hline & >Rs.5000/- & 20 & $35.71 \%$ \\
\hline Tobacco & Sometimes & 33 & $57.14 \% \%$ \\
\hline Alcohol & Sometimes & 29 & $50.0 \%$ \\
\hline Anxiety & Frequent & 57 & $100.0 \%$ \\
\hline
\end{tabular}

\begin{tabular}{|c|c|c|}
\hline Symptoms/Signs & Yes (\%) & No (\%) \\
\hline Shrinking of Penis/Female Private Part & 57 & 0 \\
\hline Retraction of Breast (female) & 8 & 0 \\
\hline Fear of Impending Death & 57 & 0 \\
\hline Tingling Sensation of Genitalia & 57 & 0 \\
\hline Weakness & 57 & 0 \\
\hline Vertigo & 57 & 3 \\
\hline Palpitation & 57 & 0 \\
\hline Sleep Disturbances & 57 & 0 \\
\hline Caused by Witchcraft/Black Magic & 57 & 0 \\
\hline Ojha/Local Treatment Received & 57 & 0 \\
\hline Feeling Cold & 37 & 20 \\
\hline Burning Sensation Whole Body,Body Pain & 57 & 0 \\
\hline Pulling of Penis & 8 & 49 \\
\hline Pain Genitalia & 57 & 0 \\
\hline Reduced Sexual Function & 12 & 45 \\
\hline \multicolumn{2}{|c|}{ Rable 2: The Symptoms and Signs } \\
Reported by the Patients
\end{tabular}




\section{ADDICTION}

Few of them had frequent consumption habit of alcohol Most of them were regular tobacco users either in the form of smoking or chewing.

\section{OBSERVATIONS}

The affected persons were at acute panic state of retracting penis inside the abdomen. It was found that affected persons looked anxious and afraid of something that might cause their death. Repeatedly concerned about their penises was retracting inside abdomen. After hearing the problems, persons from the same locality were also having experiences of similar episodes. The affected persons were more frequently seen among whom those who had anxiety disorders belonged to poor socio-economic status and poor literacy.They offered poojas/worship (Religious rituals) to god for getting relief from the sufferings. A good number of people have been affected of Koro spreading over different districts. Although, a very few people have reported to hospital for their treatment. There was social unrest in the locality in the belief that some persons have done through their Black Magic/Mantra or witchcraft. Few persons have been charged and targeted for alleged of doing so. It was further suspected of previous enmity between them.

Most of the affected patients went for their treatment to 0jhas/Tantric/local quacks/local priest. They could not rely on the medical treatment thinking that it could have been due to black magic/mantra/witchcraft.Further, itwas noteworthy to mention that anxiolytics treatment was useful for admitted persons and discharged from hospital. The episode of Koro recurs to some persons after discharge from hospital and loss their faith to medicine. They again run after local traditional healers. We observed that chanted paper having drawn with local tribal language putting names of the village leaders in the centre of the paper to influence them while sitting in panchayat. It was further clarified that the accused persons put the chanted paper inside the mouth while talking before panchayat leaders with the belief that the verdict of the panchayat sitting will be in favour of them.

\section{Treatment}

Almost all who attended to hospital and contacted during our field visit were treated with Benzodiazepine (Clonazepam $0.5 \mathrm{mg} /$ Alprazolam $0.25 \mathrm{mg} / 0.5 \mathrm{mg}$ twice or thrice daily). Supportive treatment like psychotherapy in the form of reassurance and counselling was done. Few among them were reluctant initially for counselling and treatment. They had more faith on traditional folk treatment. Even after counselling and reassurance few of them was not convinced during the time of our health camp and IEC activities in the field.

\section{Health Seeking Behaviours}

All the patients had prior information about this illness mostly from friends and neighbours. Initially patients attend to local Ojhas/Traditional healers/local priest. If not improved, then go to hospital and vice versa. Main reason for attending to hospital was shortening or shrinking of penis/genitalia and associated bodily symptoms like tingling sensation, vertigo, palpitation and bodily weaknesses and feeling coldness. They believed that when coming closer with any person suffering from Koro might spread the disease.
These beliefs created a panic atmosphere in that locality to such an extent that unaffected persons restricted their movement and go out suspiciously from home to work till the attack in the locality was subsided. In few cases, the civil administration has to interfere to control the situation for alleged charged of doing so and being assaulted physically.

\section{Traditional Prophylactic Measures}

Prophylactic traditional folk measures were also taken by unaffected persons living in the same locality where the disease occurred. The affected persons were given sacred water believed to be duly purified with folk rituals (mantra) in order to counteract the black magic. Traditional measures were taken in the form of foe treatment to the affected persons in order to remove their evil spirit.

\section{Herbal Amulets}

Armlets and amulets containing a special type of traditional folk materials like medicinal herbs were also prescribed by priests or Ojhas as therapeutic and prophylactic measure.

\section{Chanted Paper}

Many people rushed to purchase chanted amulets to prevent the disease.Patients wear papers containing lines and drawing from traditional 'mantra' after collecting from local Ojhas or traditional healers. This created such an impact that some patients living in other areas, after hearing from friends of such therapy rushed and procured the paper at high costs. The paper was meant to be inserted into the armlets and worn all the time to prevent genital symptoms.

\section{DISCUSSION}

These symptoms were exclusively seen among tribal populations of Tripura. The similar incident occurred in Tripura in the year 2010.12 Other studies from different parts of India. $6,7,8,9,10$ showed that few of the affected persons were predominantly from Hindu and few from Muslim community. Many disease symptoms like Koro also had been reported but the exact aetiology, pathogenesis and manifestations were not known. Distinction between personal and collective dimensions of Koro implies an important difference in aetiological explanation of Koro,14 i.e. culture bound aetiology and the role of organicity or physiological condition. ${ }^{15}$ It is possible to make a distinction between primary Koro (either sporadic or epidemic), in which genital shrinking is presenting complaint and secondary Koro, in which presentation with comorbid condition and other psychiatric disorder such as anxiety disorder, schizophrenia,16 depression, ${ }^{17}$ a disease of the central nervous system;18,19 or somatic conditions such as urological diseases, withdrawal symptoms of drugs. ${ }^{20,21}$

It is considered that the retraction of genitalia is not only ethno-cultural belief but also to the dramatic expression of acute anxiety and fear of impending death.15 The Koro symptoms were seen among the low literacy and poor income group of rural populations. A study reported from Kerala also showed similar result. It was reported that the migrant labourers from North India had the similar symptoms of Koro in the labour camp site in Kochi, Kerala. Many of them fled after development of the Koro symptoms. The Koro syndrome reported in Tripura were similar with other studies reported from India.7,10,22 
Folk therapy is an important component of any Culture Bound Syndrome. In addition to water cooling by watersubmersion or ice-bath, one other ritual utilised the advanced technology of copier machine. ${ }^{12}$ Both Koro and non-Koro subjects in massive numbers, procured a copy of chanted paper and a page containing lines from the holy Koran or traditional chanted papers from Hindu traditional healers. Interestingly, in 1984-85 Koro epidemic in Guangdong, China, folk therapy constituted of feeding red pepper jam, black pepper or ginger juice. ${ }^{23}$ It was also revealed from present study that many affected person performed rituals to appease the evil spirit suspected to be causing such type of illness. They also used chanted papers and wearing amulets as a protection against the disease.

Panic and anxiety in neighbourhood is a strong risk factor for any psychiatric epidemic. 24,25 Community's perception of infectivity of Koro is a dynamic force. 26,27 that speeds the epidemic, which was observed here in mass-panic reaction and adopting of folk preventive measures in massive numbers. Many persons confined to home themselves or go out very cautiously. This mass reactivity highlighted the community anxiety relating to Koro, which has further fuelled its spread in the neighbourhood. In the present study, they have heard from the previously affected persons regarding the disease. Then the hearsay and rumours spread from person to person and further it spreads to the large population group of the state.

Timely intervention by health agencies is an important measure to check the spread of any epidemic, be it medical or psychiatry and in this regard the role of medical community is crucial. ${ }^{28}$ The adequate and timely response from Health Department is crucial for interruption and further spread of such type of illness among the population. The inadequate attention or failure to recognise such illness in time at the primary health care level or delay in the recognition or reporting or giving undue importance from the health agencies lead to prolong the epidemic wave, but also pushed people to adhere to folk explanation and therapy.

Media is a very sensitive and powerful tools by which epidemic news percolates through the society. ${ }^{29}$ Assam Tribune ${ }^{30}$ made a cautious statement on this issue and in West Bengal too during the first week of the epidemic, almost all the news daily of Kolkata, Television channels covered this epidemic with very ambiguous and sensational headlines for at least 4-5 consecutive days. This helped spread the news of this "strange and mysterious disease" in a wider public circle rapidly. The epidemic waves stayed for about eight weeks. ${ }^{21}$ In the present situation in Tripura, many people of the state as a whole become aware through the news daily. But many affected people did not understand correctly the expressed contents in the local dailies. Moreover, people in the rural areas of Tripura hardly read the local dailies. It was hearsay by the people from the rural areas where people hardly read daily papers. Rather, become more and more panic. Few affected person sold out their assets and fled away from their original place and go for treatment to local traditional healers.

\section{CONCLUSION}

There are several Koro epidemics that occurred in India and repeatedly the West Bengal, Assam and Tripura were affected. It is likely that population of these states have Koro vulnerability of epidemic in nature. Males are predominantly affected within the age group of 17-30 years. So target group for preventing these conditions should be within these age groups. Further, poor literacy and low socio-economic conditions are also seen, which might be the contributing factors. Therefore, health care workers need to learn from these epidemics and prepare themselves for preventive strategies including providing appropriate management. The psychiatrist should play a leading role in the education of the local health agencies and also support media and others to enhance their knowledge about Koro. Further, various large scale IEC activities to be carried out to reach to different sections of the population in order to mitigate mass fear, anxiety and to increase the spread of rational and timely information.

\section{ACKNOWLEDGEMENT}

We are thankful to the participants without whom this would have not been possible.

\section{REFERENCES}

1. Hsien R. A consideration on Chinese concepts of illness and case illustrations. Transcultural Psychiatry Research 1963;15:23-30.

2. Yap PM. Koro-a culture-bound depersonalization syndrome. British Journal of Psychiatry 1965;111(470):43-50.

3. Yap PM. Suk-Yeong or Koro-a culture bound depersonalization syndrome. The Bulletin of the Hong Kong Medical Association 1964;16(1):31- 47.

4. Rin H. A study of the aetiology of koro in respect to Chinese concept of illness. Int J Soc Psychiatry 1965;11:713.

5. Hsien R. A study of aetiology of koro in respect to Chinese concept of illness. International Journal of Social Psychiatry 1965;11:7-13.

6. Chowdhury AN, Pal P, Chatterjee A, et al. Analysis of north Bengal koro epidemic with three years follow up. Indian Journal of Psychiatry 1988;30(1):69-72.

7. Dutta D. Koro epidemic in Assam. British Journal of Psychiatry 1983;143(3):309-10.

8. Chowdhury AN, Banerjee G, Sen KD, et al. Koro in West Bengal again. Indian Journal of Social Psychiatry 1994;10:27-30.

9. Roy D, Hazarika S, Bhattacharya A, et al. Koro: culture bound or mass hysteria? Australian NewZealand Journal of Psychiatry 2011;45(8):683.

10. Promodu K, Nair KR, Pusparajan S. Koro syndrome: mass epidemic in Kerala, India. Indian Journal of Clinical Psychology 2012;39(2):152-6.

11. Ranga K. The curious cases of shrinking genitalia: mass panic at labour camp in Goregaon as twenty five men suffer from retracting genitalia. Mid-Day, 26.10.2010.Availableon the Internet at http://www.midday.com/news/2010/oct/261010-labour.

12. Ghosh S, Nath S, Brahma A, et al.Fifth koro epidemic in India: a review report. World Cultural Psychiatry Research Review 2013;8(1):8-20. 
13. Tripura profile. Census 2011. Censusindia.gov.in/2011census/censusinfodashboard/.../ IND016_Tripur.

14. Atalay H. Two cases of koro syndrome or anxiety disorder with genital retraction fear. Turkish Psychiatry Derg 2007;18(3):282-5.

15. Chowdhury AN. Sex guilt cognition in the genesis of koro. Archives of Indian Psychiatry 1996;3:52-9.

16. Altable RC, Urrutia RA. Koro-misidentification syndrome in schizophrenia? a plea for clinical psychopathology. Psychopathology 2004;37(5):249-52.

17. Freudenmann RW, Schonfeldt-Lecuona C. Koro-like symptoms in a recurrent depressive disorder. Nervenarzt 2005;76(7):883-7.

18. Dzokoto VA, Adams G. Understanding genital-shrinking epidemics in West Africa: koro, juju or mass psychogenic illness? Cultural Med Psychiatry 2005;29(1):53-78.

19. Kar N. Cultural variations in sexual practices. In: Kar N, Kar GC. eds. Comprehensive textbook of sexual medicine. New Delhi: Jaypee Brothers Medical Publishers 2005.

20. Bernstain RL, Gaw AC. Classification of Amok in DSM-IV. Hospital \& Community Psychiatry 1992;43(8):789-93.

21. Earleywine M. Cannabis-induced koro in Americans. Addiction 2001;96(11):1663-6.

22. Chowdhury AN. Cultural koro and Koro-Like Symptom (KLS). German Journal of Psychiatry 2008;11:81-2.
23. Tseng WS, Mo KM, Hsu J, et al. A sociocultural study of koro epidemics in a Guangdong, China. American Journal of Psychiatry 1988;145(12):1538-43.

24. Chowdhury AN. Psychopatho-sexuality in Koro patients. Journal of Indian Academy of Applied Psychology 1992; 18(1-2):57-60.

25. Cheng ST. Epidemic genital retraction syndrome: environmental and personal risk factors in southern China. Journal of Psychology \& Human Sexuality 1997;9(1):57-70.

26. Chowdhury AN. Koro social response (urban): a longitudinal study of north Bengal koro epidemic. Indian Journal of Psychiatry 1992;34(1):46-52.

27. Tseng WS, Mo KM, Li LS, et al. Koro epidemic in Guangdong, China. A questionnaire survey. Journal of Nervous and Mental Disease 1992;180(2):117-23.

28. Chowdhury AN. Personality profile of koro patients. Journal of Personality \& Clinical Studies 1991;7(1): 117-18.

29. Small GW, Borus JF. The influence of newspaper reports on outbreaks of mass hysteria. Psychiatric Quarterly 1987;58(4):269-78.

30. Assam Tribune. It's a cultural syndrome, say doctors. 30.11.2010.

http://www.assamtribune.com/scripts/detailsnew.asp?i $\mathrm{d}=\operatorname{sep} 3010 /$ city06. 